\title{
Challenges and Opportunities in Remote Laser Welding of Steel to Aluminium
}

\author{
Hiren R. Kotadia ${ }^{1, *}$, Pasquale Franciosa ${ }^{1}$, and Dariusz Ceglarek ${ }^{1}$ \\ ${ }^{1}$ Warwick Manufacturing Group, University of Warwick, Gibbet Hill Road, Coventry CV4 7AL, UK
}

\begin{abstract}
In the last two decades, the automotive industry has been facing demands to reduce fuel consumption and to meet $\mathrm{CO}_{2}$ emissions through applications of lightweight materials. Therefore, aluminium alloys have replaced substantial amounts of steel; and they are receiving significant attention to achieve greenhouse emission targets. However, a critical factor in applications of advanced aluminium in automotive Body in White (BIW) designs depends on availability of cost effective and high performance joining processes. Currently, a Self-Pierce Riveting (SPR) process is extensively used for aluminium BIW sheet metal parts joining which is expensive, additionally increase the weight of the vehicle and cause inefficiency in manufacturing operations. As aluminium alloys are difficult to weld by conventional technologies such as electrical resistance spot welding, MIG arc welding etc., various joining technologies had proposed to weld aluminium alloys and dissimilar alloys over the years. Often, these technologies restrict design flexibility and are expensive for mass production. In this context, Remote Laser Welding (RLW) has gained popularity because of its distinct advantages such as design flexibility, production speed, material and cost savings. This paper provides a critical review of challenges and opportunities for application of RLW to dissimilar metal welding of steel to aluminium. Next steps of research and development are also highlighted.
\end{abstract}

\section{Introduction}

Steel and aluminium are most commonly used structural material. Steel is widely used in automotive application because of its high tensile strength and low cost [1]. The average use of AHSS in body in white (BIW) design has increased significantly over the past 20 years [2]. The advantages of AHSS is not only reduced BIW weight but also enhance their crashworthiness [3]. However, considering the stiffness required of each components, there is a certain limit to the reduction of weight with thinner AHSS sheets [2]. Aluminium (Al) have advantage over the steel because of its strength-toductility ratio, toughness and its inherent corrosion resistance with no need for an additional coating step [4]. $\mathrm{Al}$ alloys emerged as most promising candidate basis on high volume manufacturing and cost, in compare with the other potential lightweight candidate magnesium alloys and carbon fiber reinforced polymer. In addition to that, wrought $\mathrm{Al}$ alloys have advantages over overall body stiffness and impact energy absorption. Nevertheless, it is unlikely that automobiles can ever be manufactured using only aluminium for applications. It therefore becomes important to develop strategies and techniques, which can join dissimilar metals such as aluminium to steel [5].

The combination of steel and aluminium alloys can provide excellent combination of good properties (low density and/or good corrosion resistance for Al alloys and good formability and strength for steel) of BIW at low material cost; therefore, dissimilar joints have significant importance in automotive and other engineering applications [6]. Hence, required better solidification science understanding specifically to understand influence of joining techniques and their influence on the resulting microstructure. One of the main scientific and technical challenge is $\mathrm{Al}_{\mathrm{x}} \mathrm{Fe}_{\mathrm{y}}$ intermetallic compounds (IMCs) from solidification, which is responsible to detriment joint properties [6] . Current solution to overcome these challenges is to use riveting or friction stir welding [7]. Riveting (e.g. SelfPierce Riveting (SPR)) is a high-speed cold mechanical joining process used to join two or more sheets of materials. This method used typically for steels and aluminium alloys sheet. It is a single-step technique, generally using a semi-tubular rivet to clinch the sheets in a mechanical joint. While friction welding is solid state joining process and the material undergoes intense plastic deformation at elevated temperature [8].

There is no side effect on substrate but have limitation such as excess to both side of the material and processing time in compare with the resistance spot welding (RSW) and Laser welding techniques. Simultaneously, Remote Laser Welding (RLW) have attracted various automotive OEMs to joints aluminium and steel for BIW applications. The advantages of RLW 
are successfully demonstrated shorten welding time, single sided non-contact joining process will provide design flexibility and material saving i.e. reducing flange size, lower operating costs etc., in compare with the RSW [9] [10].

The main aim of this article is to explain recent experimental work focused on using RLW for joining dissimilar sheet metal parts made of steel and aluminium. The experimental results and analysis of microstructure formation are discussed with opportunities.

\section{Experimental procedure}

\subsection{Welding experiment}

A $6 \mathrm{~kW}$ diode laser (LaserLine $\mathrm{GmbH}$, Germany), with a beam parameter product of $6 \mathrm{~mm}$ mrad was used. The laser beam was delivered through an optical fiber of 150 I $\mathrm{m}$ diameter and coupled with the WeldMaster remote welding head (Precitec GmbH, Germany), which comes with $150 \mathrm{~mm}$ collimating lens, and $300 \mathrm{~mm}$ focal length. The resulting Rayleigh length is $2.76 \mathrm{~mm}$. No shielding gas nor filler wire was used for the trials.

\subsection{Materials}

The material used in this study is commercially available $1.5 \mathrm{~mm}$ thick 5182 aluminium (Al-4.3 Mg) sheet and a 590DP steel (Fe-1.65Mn-0.055C) sheet with $\mathrm{Zn}$ coated. All compositions in this article are given in weight percent unless otherwise stated.

\subsection{Materials}

After welding experiments, samples were sectioned and polished with SiC papers and $0.25-\mu \mathrm{m}$ silica suspension solution. Then, at first preliminary examination was done using an optical microscope followed by the detailed examination of the microstructure and identification of the phase composition by using an Sigma FEG Scanning Electron Microscope (SEM) equipped with energy-dispersive X-ray spectroscopy (EDX).

\section{Results and discussion}

Current challenges exist in RLW described in following three section with the opportunities

\subsection{Weld pool heterogeneity and heat management}

RLW joining resulted in the formation of complex and heterogeneous microstructures composed of columnar grains and solute band (Fig. 1a to c). Adjustment to weld, small grain size $(\sim 14 \mu \mathrm{m}$ vs $34 \mu \mathrm{m}$ in the base material) heat effected zone was evident in $\mathrm{Fe}$ and $\mathrm{Al}$ sheet side. Experimental results shown solute bands (white, gray and back in colour contrast) throughout the melt pool, which is further distinctly, identified through EDS maps in Figure 1d. These solute bands were more frequent when steel penetration increased. Their origin can be explained by entrapped solid aluminium in steel liquid due to the upward convection movements occurring at high temperature on melt-pool. In addition to that, hot-cracks and porosity were evidenced in weld area. The great difference in melting temperatures between steel and aluminium and tendency to form cellular or columnar dendritic growth with long channels of inter-dendritic liquid trapped between them leading to cavities and hot tearing. The porosity mainly attributed to shrinkage, hydrogen gas entrapment in the melt pool, irregular melt flow and blowholes [11]. Often, aluminium alloys (especially 6xxx alloy) are highly susceptible to hot-cracking cracking after laser welding due to the high thermal expansion (approximately twice that of steel) and the large change in volume during the solidification.

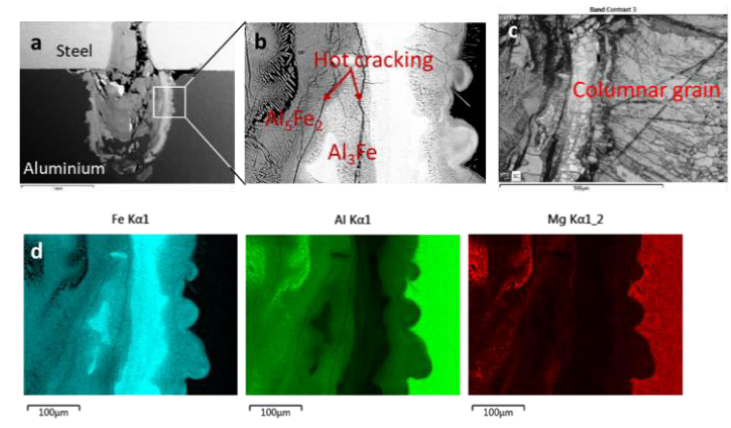

Fig. 1. Weld cross section: (a) weld pool, (b) magnified microstructure, (c) band contrast image showing columnar grain in weld and (d) EDS maps showing non-uniformity of weld.

This hot cracking phenomena can be controlled by reducing welding speed by reducing cooling rate, producing fine equiaxed weld structure, using pulse shaping and dual beam laser system, it is demonstrated in $2 \mathrm{xxx}, 6 \mathrm{xxx}$ and $7 \mathrm{xxx}$ series of aluminium alloys [11]. The weld profile also plays important role in crack sensitivity [12]. It can be tailored by using an electromagnetic, ultrasonic vibration to improve the penetration depth and enhance mixing in weld pool in order to achieved homogeneous structure [13]. Also, proposed laser-brazing option in order to avoid brittle IMCs formations [11]. In brazing joint two base metals together filling the gap by melting lower melting point metal and it fused the based metal (steel) and prevent IMCs. However, in this option to obtained desire joint strength must require filler metal. Another potential alternative for homogeneous weld pool can be address through managing heat by using the conduction mode instead of the keyhole mode. In conduction mode, the laser power density is adequate to melt base metal and subsequently heat is conducting down into the metal from the surface. The poser density of the laser spot was controlled so that the imposed energy can transferred through the steel plate to the aluminium or vice versa and create joint (Fig. 2a). In this mode, it is essential to determined energy input respect to alloy properties and thickness in order to avoid partial melting or excessive IMCs growth/ HAZ. While in keyhole mode, welding 
the power density is great enough that the metal goes beyond just melting and metal vaporised. The vaporizing metal creates increasing gas that pushes outward and this creates a keyhole or channel from the surface down to the depths of the weld (Fig. 1b) and generate diverse weld pool composition, which likely to generate segregation bands and cracks.

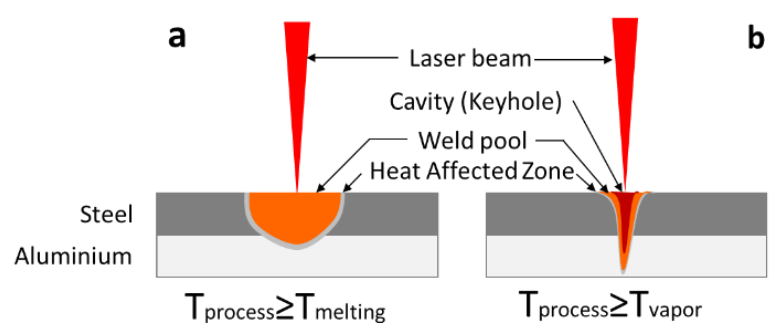

Fig. 2. Schematic representation of (a) conduction mode; and, (b) keyhole mode.

\subsection{Intermetallics}

In current investigation, two-overlap configuration were used in keyhole mode heating. SEM micrographs from weld cross section are presented in Fig. 1a and 3a illustrating overall microstructure. The microstructure consists of primary $\alpha-\mathrm{Al}$ and ferritic-martensitic microstructure in aluminium and steel sheet side, respectively with $\mathrm{Fe}_{\mathrm{x}} \mathrm{Al}_{\mathrm{y}} \mathrm{IMCs}$ phases (Fig. 3b and c). Primary columnar grain are grow over few hundred microns. These columnar grains are grown from weld interface to centre due to the temperature gradient during the cooling. During the rapid cooling entrapped aluminium surrounded by steel liquid could form first locally $\mathrm{Fe}-\mathrm{Al}$ reach chemical composition after $\mathrm{Al}$ diffused in to $\mathrm{Fe}$ liquid and subsequently form $\mathrm{Al}_{3} \mathrm{Fe}$, $\mathrm{Al}_{5} \mathrm{Fe}_{2}$ IMCs and remaining liquid solidified as pure $\mathrm{Al}$ or Fe (Fig. 3).
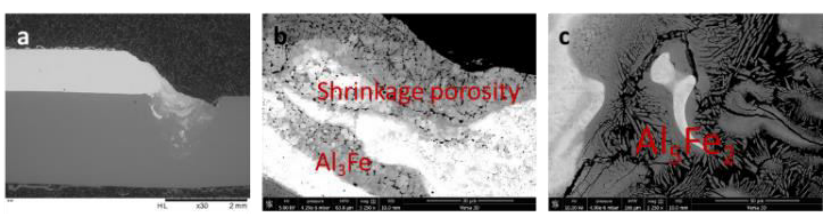

Fig. 3. Lap-shear weld cross section: (a) weld pool, (b) and (c) higher magnified microstructure showing IMCs and porosities.

Although, $\mathrm{Fe}$ is highly soluble in liquid aluminium and its alloys, it has very little solubility in the solid (max. 0.05 wt. \%, 0.025 at. \%) and so it tends to combine with other elements such as $\mathrm{Al}, \mathrm{Si}, \mathrm{Mn}, \mathrm{Cu}$ etc to form intermetallic phase particles of various types: $\beta$ ' $(\mathrm{AlFe}), \beta "\left(\mathrm{AlFe}_{3}\right)$ - can be observed on the Fe-rich side of the $\mathrm{Al}-\mathrm{Fe}$ phase diagram (Fig. 4). The Al-rich side shows three phases: $\zeta\left(\mathrm{Al}_{2} \mathrm{Fe}\right), \eta\left(\mathrm{Al}_{5} \mathrm{Fe}_{2}\right)$, and $\theta$ $\left(\mathrm{Al}_{13} \mathrm{Fe}_{4}\right)$ [14]. The Al-rich side of the diagram presents a eutectic reaction in which the $\mathrm{Fe}$ - containing $\mathrm{Al}$ melt decomposes into $\theta$ phase $\left(\mathrm{Al}_{13} \mathrm{Fe}_{4}\right)$ and $\mathrm{Al}$ [6]. Apart from these 'equilibrium' phases, several metastable compounds, for example the monoclinic phase $\mathrm{Al}_{6} \mathrm{Fe}$, have been observed in rapidly solidified $\mathrm{Al}-\mathrm{Fe}$ melts.
Table 1 summarised the most common intermetallic phases identified in Fe/Al welding. These IMCs can be controlled and supressed by addition of alloying elements like $\mathrm{Si}, \mathrm{Mg}$ and $\mathrm{Zn}$. These elements can be added into weld pool through filler wire or powder or changing local surface chemistry of the base material.

Another approach is to control IMCs through the thick coating layer of $\mathrm{Al}$ and welded through conduction mode, which may allow more stable and continuous intermetallics at interface. Nevertheless, to achieve this desirable IMC depend on three factors [6]: (i) chemical composition, (ii) nucleation and growth by interdiffusion process, and (iii) mobility of the constituent elements. Therefore, fundamental understanding of nucleation and growth by incorporating welding condition is desired for development of dissimilar metal joining.

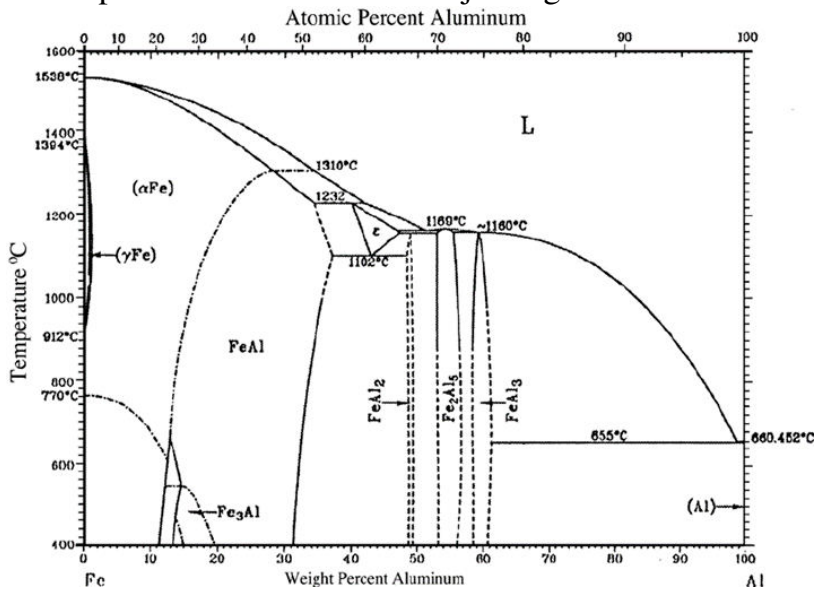

Fig. 4. Binary Al-Fe phase diagram [15].

Table 1. Summary of the most common intermetallic compounds (IMCs) identified in the steel/Aluminium fusion joints.

\begin{tabular}{|c|c|}
\hline Alloys & Composition \\
\hline \multirow[t]{5}{*}{$\mathrm{Al}$ (wrought alloys)/Fe } & $\mathrm{AlFe}$ \\
\hline & $\mathrm{AlFe}_{3} \mathrm{C}$ \\
\hline & $\mathrm{Al}_{3} \mathrm{Fe}$ \\
\hline & $\mathrm{Al}_{5} \mathrm{Fe}_{2}$ \\
\hline & $\mathrm{Al}_{13} \mathrm{Fe}_{4}$ \\
\hline \multirow{5}{*}{$\begin{array}{l}\mathrm{Al} \text { (Cast or wrought } \mathrm{Al} \text { alloys } \\
\text { with higher } \mathrm{Si} \text { )/Fe }\end{array}$} & $\mathrm{Al}_{2} \mathrm{Fe}_{3} \mathrm{Si}_{3}$ \\
\hline & $\mathrm{Al}_{3} \mathrm{FeSi}$ \\
\hline & $\mathrm{Al}_{2} \mathrm{FeSi}$ \\
\hline & $\mathrm{Al}_{8} \mathrm{Fe}_{2} \mathrm{Si}$ \\
\hline & $\mathrm{Al}_{4} \mathrm{Fe}_{1.7} \mathrm{Si}$ \\
\hline $\mathrm{Al}$ (excessive $\mathrm{Zn}$ )/Fe & $\mathrm{Al}_{5} \mathrm{Fe}_{2} \mathrm{Zn}_{0.4}$ \\
\hline
\end{tabular}

\subsection{Stress on weld structure}

The residual stress problem is arising due to the temperature varies with the position during the welding process. This can be overly complicated when phase- 
changes at various zones and differences in the coefficient of thermal expansion and thermal conductivity of the base metal e.g. Fe and $\mathrm{Al}$ dissimilar welding. A number of investigators have studied joint failures and often-noticed high value of residual stress is concentrated in HAZ, adjacent to the weld interface [16]. Where, RLW process have advantages over the other techniques to form smaller HAZ due to the local rapid heating. Especially, welding speed and laser power has the strongest effect on the residual stress among other parameters e.g. increasing weld speed and lower power decreases residual stresses [17]. However, RLW process control is challenging due to the complicated physical phenomena-taking place during the welding. Therefore, optimisation of laser welding process is usually challenging when change in weld configuration and/or material. The optimisation of RLW usually based on the welding experiments and trial error approach, which is often time consuming and expensive [18]. Completely new avenue of the research potentially required to address through novel modelling toolsets and systematic experiments.

\section{Concluding remark}

1. In thin sheet dissimilar welding, the formation of the a keyhole is undesirable mainly because of uncontrolled mixing lead to diverse chemistry of weld pool, defects like hotcracking and porosity through segregation, in compare with the conduction mode. However, conduction mode have own limitation to weld only definite configuration.

2. Fe- rich IMCs observed when $\mathrm{Fe} / \mathrm{Al}$ welded through keyhole mode condition. The formation of IMCs depend on the weld pool chemical composition, nucleation and growth mechanism through inter-diffusion process and the mobility of the solutes elements. Heterogeneous melt pool chemical composition observed and its lead to formation of $\mathrm{Al}_{3} \mathrm{Fe}$ and $\mathrm{Al}_{5} \mathrm{Fe}_{2}$ IMCs with cracks and porosity. Since IMCs phase detrimental to the properties of joints, a fundamental understanding of solidification science is vital for dissimilar metal welding.

3. Understanding about RLW parameter is vital in order to control weld pool geometry / keyhole, microstructure and residual stress and its relation to joint properties.

All challenges are interwoven and are unlikely to be solved individually; rather, a holistic approach is required, where the solution to one challenge guides the approach used to tackle another.

This study was partially supported by the WMG Centre High Value Manufacturing Catapult and the UK EPSRC project EP/K019368/1: Self-Resilient Reconfigurable Assembly Systems with In-process Quality Improvement. Additionally, the authors would like to acknowledge the support of the characterisation facility by the Higher Education Funding Council for England (HEFCE) fund.

\section{References}

1. E. Ghassemieh, IntechOpen, 355 (2011). DOI: 10.5772/13286.

2. L. Christian, K. Norbert, K.F. B., Steel Res. Inter. 88(10), 1700210 (2017).

3. P.K. Mallick, Materials, A volume in Woodhead Publishing Series in Composites Science and Engineering, 1-32 (2010).

4. J. Davis, ASM Specialty Handbook: Aluminum and Aluminum Alloys, ASM International (1993).

5. H.K.D.H. Bhadeshia, Sci. Tech. Welding and Joining, 20(6), 451 (2015).

6. H. Springer, A. Kostka, E.J. Payton, D. Raabe, A. Kaysser-Pyzalla, G. Eggeler, Acta Mater. 59(4) (2011) 1586-1600.

7. S.D. Meshram, T. Mohandas, G.M. Reddy, J Mat. Proc. Tech. 184(1), 330 (2007).

8. D. Li, A. Chrysanthou, I. Patel, G. Williams, Inter. J Adv. Manuf. Tech. 92(5), 1777 (2017).

9. D. Ceglarek, M. Colledani, J. Váncza, D.-Y. Kim, C. Marine, M. Kogel-Hollacher, A. Mistry, L. Bolognese, CIRP Annals, 64(1), 389 (2015).

10. P. Franciosa, D. Ceglarek, CIRP Annals, 64(1) 149 (2015).

11. K.-M. Hong, Y.C. Shin, J Mat. Proc. Tech. 245, 46 (2017).

12. A. El-Batahgy, M. Kutsuna, Adv. Mat. Sci. Eng. 2009, 1, Article ID 974182 (2009).

13. V.V. Avilov, A. Gumenyuk, M. Lammers, M. Rethmeier, Sci. Tech. Welding and Joining 17(2) 128 (2012).

14. O. Kubaschewski, IRON_Binary Phase Diagrams Berlin: Springer Verlag; (1982).

15. T.B. Massalski, H. Okamoto, P.R. Subramanian, L. Kacprzak, Binary Alloy Phase Diagrams, 2nd Edition, ASM International (1990).

16. P.J. Withers, Reports on Progress in Physics 70(12) (2007) 2211.

17. E.M. Anawa, A.G. Olabi, J Mat. Proc. Tech. 204 (1) 22 (2008).

18. E.C. Ozkat, P. Franciosa, D. Ceglarek, J Laser App. 29(2) 022423 (2017). 